\title{
Thermal power stabilization of shapes of non-rigid shafts
}

\author{
Alexander V. Bobrowskii ${ }^{1,}$, Oleg I. Drachev ${ }^{1}$, Igor V. Turbin ${ }^{1}$, Vyacheslav E. Epishkin ${ }^{1}$ \\ ${ }^{1}$ Togliatti State University, 445667Belorusskaya St., 14, Togliatti, Russian Federation
}

\begin{abstract}
This article reviews the design of thermal power units for performing thermal operations of hardening and tempering of nonrigid parts of the "shaft" type. The authors describe the thermal power treatmenttechnology, the residual deformation analysis and the optimal conditionsdefinition. The units operation principles and algorithms are given.
\end{abstract}

\section{Introduction}

The ever-growing requirements for the machines quality entail the increased requirements for the accuracy of non-rigid parts (NRP) and, therefore, for the creation of advanced technologies of their manufacturing. The achievement of high precision of NRP manufacturing is contingent on heavy material costs and labor intensity and is closely connected with manufacturing productivity. That is why the task of increasing the accuracy and productivity of NRP is one of the most importantnational economic goals of machine manufacturing. Thesearchforreservesof increasing exploitation accuracy and manufacturing productivityis an essential scientific problem of machine manufacturing technology. The current experience shows that the traditional treatment methods are not efficient enough for the NRP manufacturing.

\section{Importance and goal of this research}

That is why in practice the issues of manufacturing non-rigid parts are solved by applying multicycleheat treatment and multipass turning process, by reducing the cutting modes and applying the additional manual finishing operations, which is uneconomical and inefficient.In addition, the accuracy and stability of the part shape depend on the technological process structure, taking into consideration the operations' interconnections and technological heredity, which is transmitted by the workpiece material itself. The most promising directions for solving the problem of the NRP manufacturing are the technological methods that form the internal residual stresses in the elastic-plastic state on the basis of the thermal power treatment (TPT) of impact on the shaft workpiece (SW), while providing uniformityand steadiness of distribution of plastic deformations and residual stresses throughoutthe SW [1-5].

\footnotetext{
${ }^{*}$ Corresponding author: ba838@yandex.ru
} 


\section{Presentation of basic material}

In order to increase the TPT productivity during hardening, we designed and tested a unique unit that allowed to process $4 \div 16$ SW simultaneously due to its construction efficiency [6]. The unit includes the frame madein the form of tubes that screw into each other, thus expanding the technological capabilities of the TPT unit, because it can be set up to process shaft workpieces of various lengths due to the screwed mechanism of their fixation.

The parabolic profile tubes allow to increasethe axial force applied to the processed SW through the increase of the frame rigidity by using the equal rigidity profile.

The placement of the filler in the central part of the frame increases its rigidity due to its cavity being filled and increases the cooling time, which makes it possible to apply the tension load during the SW cooling stage.

The placement of the filler in the cavity covered on both sides with screw plugs improves the working conditions by reducingthe premise gas contamination, since the contact of cooling liquids and the filler is excluded. The scheme of the TPT unit design is shown in Fig. 1, and the general view of the laboratory unit is shown in Fig. 2.

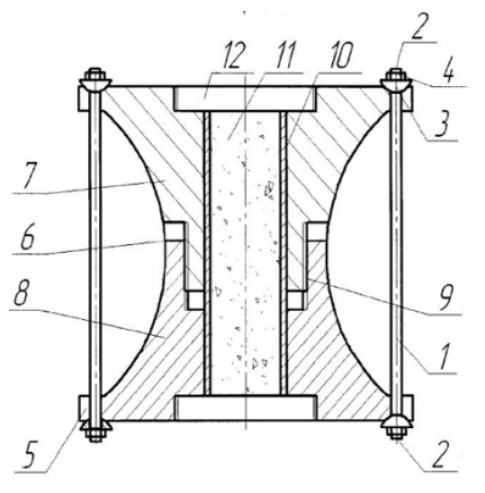

Fig. 1. The scheme of the TPT unit design

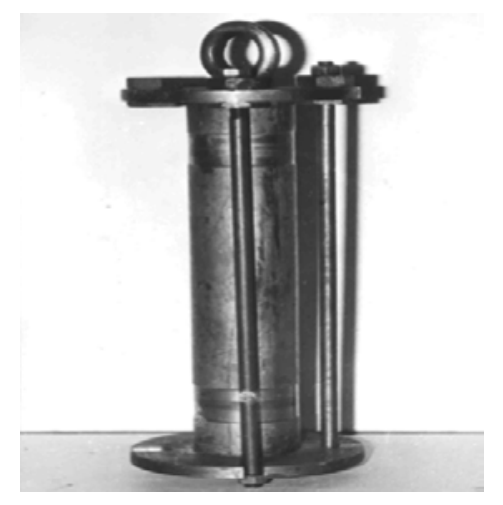

Fig. 2. The general view of the laboratory unit

SW 1 have threaded ends 2 with spherical washers 3 and screws 4 placed on them; the shaft workpieces are installed into slots 5 of frame 6 . Frame 6 consists of two parabolic profile tubes: upper tube 7 and lower tube 8 . Tubes 7 and 8 are connected by screw thread 9. Frame 6 contains cavity 10 with filler 11 (sand, cast-iron shot). Cavity 10 is covered on both sides with screw plugs 12. The linear expansion coefficient of frame 6 is higher than that of SW 1.

The TPT unit works in the following way. After the fixation of SW 1 with the help of spherical washers 3 in slots 5 of frame 6, the unit is heated up to working temperatures. Since the linear expansion coefficient of frame 6 is higher than that of the SW, accordingly, the SW elongation is greater. During the cooling stage, due to the greater heat capacity, frame 6 cools slower than workpiece 1, which makes it possible to maintain their strained condition throughout the entire processing cycle.The length of frame 6 for SW 1 of a different lengthcan be adjustedby the relative rotation of upper tube 7 and lower tube 8 . The body of the laboratory unit (Fig.2) is cylindrical, but even this design provided positive results. After the application of the developed TPT method, the finished products distortion does not exceedthe accuracy requirements specified by the drawing throughout the exploitation period. 
The technical results of the developed NRP technology are the increase of the parameters accuracy and stability, the increase of the finished productsoperational accuracy through the creation of uniform alternating residual stresses throughout the workpiece length [7-9].

The disadvantage of this unit design is the fact that it is impossible to correct the axial curvature of the shaft workpiece. In order to eliminate this disadvantage, we improved the thermal power treatment technology; additionally, the preliminary heating of the SW with the fixtures installed on it is carried out simultaneously with the frame cooling. The temperatures of the shaft workpiece heating and the frame cooling are selected based on the condition ofexceeding the yield limit during the simultaneous heating of the SW fixed in the frame.

The preliminary installation of the fixtures on the shaft workpiece allows to reduce the time of its installation in the frame, to set the required distance between the SW supports; between these supports it will be subject to axial deformation.

The preliminary heating of the SW and the simultaneous cooling of the frame make it possible to increase the difference between the thermal elongations of the SW and the frame and this way to exceed the yield limit during the axial tension and to compensate for the deflection of the shaft workpiece with the greater curvature.

The TPT technology is applied in the following manner. Spherical washers 3 and screws 4 are placed on threaded ends 2 of SW 1 (Fig. 1) and are heated, for example, in shaft furnaces,electric furnaces or muffle furnaces. At the same time frame 6 is cooled, for example, with the help of a vapor compression refrigerating machine or a cascade machine. After that the SW is fixed in the frame and the simultaneous heating of the frame and the SW is performed. The deformation of the frame and the SW takes place due to the difference between their thermal elongations. When certain aspects are varied (the coefficient of thermal expansion of the material of frame 6 , the degree of preliminary heating of SW 1, the cooling of frame 6 , the distance between the fixture washers 2), the value of workpieces axial deformation is regulated as the difference between the thermal elongations of SW and frame 6 (Fig.3)

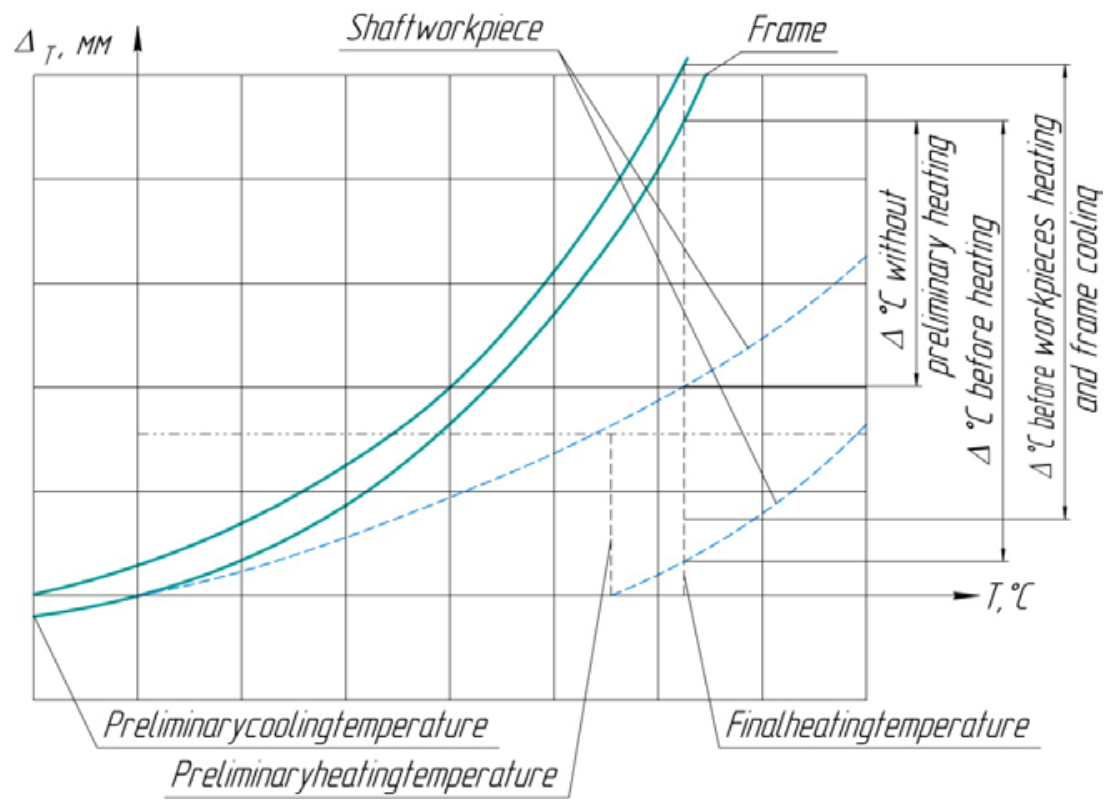

Fig. 3. Graph of the dependence of the SW and frame temperature elongations with the difference of their elongations during heating 
The general algorithm for calculating the frame and workpiece elongations is the following:

1. The SW geometry is defined: length, diameter, deflection.

2. The required elongation is calculated to select the deflection.

3. With consideration to clause 2, the value of the required force elongation $\varepsilon_{T}^{\Sigma}$ of the workpiece is defined in order to exceed the material yield limit.

4. The thermal elongation of the frame at the working temperature is defined; the difference between the frame and the workpiece elongations is calculated on the basis of that elongation.

5. If it is not possible to achieve this difference, the workpiece with fixtures is preliminary heated to the temperature when the workpiece will become elongated up to the value exceeding the required difference. After that the workpiece is installed into the cold frame.

6. If the difference is greater than the required one, a gap is provided when fixing the workpiece in the clamp.

In order to ensure the $1-5 \%$ residual deformation of the SW, the stresses above the yield limit are created in its cross section areas. At that, the changes of the elastic modulus and the yield limit of the frame and the SW in dependence to the temperature are taken into consideration.

The values of the yield limit of the frame and SW materials in dependence to the temperature (for $100,300,500{ }^{\circ} \mathrm{C}$ ):

$$
\begin{aligned}
& \sigma_{\mathrm{T}}^{100}=230 \mathrm{MPa} ; \sigma_{\mathrm{T}}^{300}=200 \mathrm{MPa} ; \sigma_{\mathrm{T}}^{500}=170 \mathrm{MPa} . \\
& \sigma_{\mathrm{T}}^{100}=760 \mathrm{MPa} ; \sigma_{\mathrm{T}}^{300}=690 \mathrm{MPa} ; \sigma_{\mathrm{T}}^{500}=440 \mathrm{MPa} .
\end{aligned}
$$

The elastic moduli for the frame and the workpiece in dependence to the temperature:

$\mathrm{E}^{100}=1,98 \cdot 10^{5} \mathrm{MPa} ; \mathrm{E}^{300}=1,85 \cdot 10^{5} \mathrm{MPa} ; \mathrm{E}^{500}=16,9 \cdot 10 \mathrm{MPa}$.

$\mathrm{E}^{100}=2,15 \cdot 10^{5} \mathrm{MPa} ; \mathrm{E}^{300}=2,01 \cdot 10^{5} \mathrm{MPa} ; \mathrm{E}^{500}=1,69 \cdot 10^{5} \mathrm{MPa}$.

The temperature deformation of the frame and the shaft is presented by the function $\varepsilon T=\alpha(T) \cdot T$, where $\alpha(T)$ is the material linear expansion coefficient that depends on the temperature, $\mathrm{mm}$ /degree; and $\mathrm{T}$ is the heating temperature in degrees.

Below we give the example of application of the developed technology. The frame is made of steel 12X18H9T, the shaft workpiece is made of steel 40XH2M. The frame length is $\mathrm{L}=300 \mathrm{~mm}$, the SW length is $\mathrm{l}=270 \mathrm{~mm}$, the outside diameter of the frame is $\mathrm{D} 1=90$ $\mathrm{mm}$, the inside diameter of the frame is $\mathrm{D} 2=70 \mathrm{~mm}$, the shaft diameter is $\mathrm{d}=30 \mathrm{~mm}$. The SW initial curvature is $1 \mathrm{~mm}$. A shaft electric furnace with the heating temperature up to $1250{ }^{\circ} \mathrm{C}$ is used for the heating. A vapor compression refrigerating machine with the cooling temperature down to minus $60{ }^{\circ} \mathrm{C}$ is used for the frame cooling. When a cascade refrigerating machine is used, the cooling temperature can be down to minus $120{ }^{\circ} \mathrm{C}$.

The absolute elongations $\Delta \mathrm{L}$ of the frame with the length of $300 \mathrm{~mm}$ during its heating with consideration to the change of the linear expansion coefficient at temperatures of 100 , 300, $500{ }^{\circ} \mathrm{C}$ are the following:

$$
\begin{aligned}
& \Delta l_{\mathrm{CT}}^{100}=16,8 \cdot 10^{-6} \cdot 300 \cdot 80=0,41 \mathrm{~mm} ; \\
& \Delta l_{\mathrm{CT}}^{300}=17,3 \cdot 10^{-6} \cdot 300 \cdot 280=1,45 \mathrm{~mm} ; \Delta l_{\mathrm{CT}}^{500}=18 \cdot 10^{-6} \cdot 300 \cdot 480=4,15 \mathrm{~mm} .
\end{aligned}
$$

The elongations of the shaft in the fixture with the length of $270 \mathrm{~mm}$ during its heating with consideration to the change of the linear expansion coefficient at temperatures of 100 , 300, $500{ }^{\circ} \mathrm{C}$ are the following (Fig. 4): 


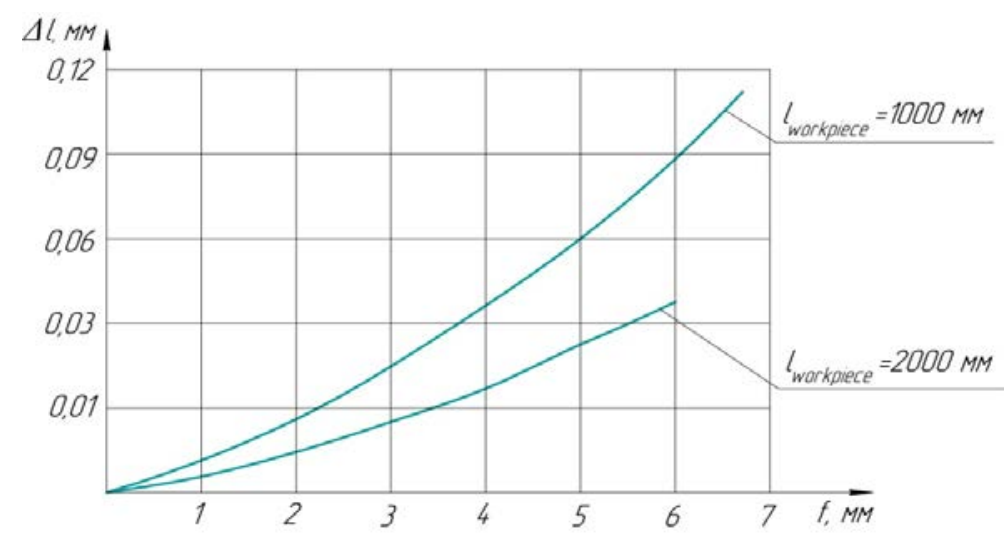

Fig. 4. Graph of the dependence of the frame and SW temperature elongations.

$\Delta l_{\mathrm{SW}}^{100}=11,4 \cdot 10-6 \cdot 270 \cdot 80=0,26 \mathrm{~mm} ; \Delta \mathrm{l}_{\mathrm{SW}}^{300}=12,3 \cdot 10-6 \cdot 270 \cdot 280=0,93 \mathrm{~mm}$;

$\Delta l_{\mathrm{SW}}^{500}=14 \cdot 10-6 \cdot 270 \cdot 480=1,81 \mathrm{~mm}$.

The respective relative deformations are the following:

Frame: ${ }^{100}=0,001344 \% ;{ }_{T}^{300}=0,004844 \% ;{ }^{500}=0,00864 \%$.

Workpiece: ${ }^{100}=0,00096 \% ; \varepsilon_{T}^{300}=0,00344 \% ;{ }_{T}^{500}=0,00672 \%$.

The tensions calculated by the formula are compared to the yield limit: $\sigma_{\mathrm{T}}=\mathrm{E}_{\mathrm{SW}} \cdot \Delta \varepsilon_{\mathrm{T}}<\sigma_{\mathrm{Y}}$, where $\mathrm{E}_{\mathrm{SW}}$ is the workpiece elastic modulus; $\Delta \varepsilon_{\mathrm{T}}$ is the difference between the temperature deformations of the frame and the workpiece; $\sigma_{\mathrm{Y}}$ is the yield limit at the respective temperature.

In order to correct the initial curvature of the shaft, it is necessary to determine the additional elongation. The shaft curvature is described by the sinusoid

$$
y=f \cdot \sin (\pi x / L),
$$

where $\mathrm{f}$ is the curvature value; $\mathrm{L}$ is the shaft length; $\mathrm{x}$ is the coordinate of the cross section lengthwise.

The value of the elongation $\Delta \mathrm{l}_{\mathrm{r}}$ for the curvature compensation is

$$
\Delta \mathrm{l}_{\mathrm{r}}=\pi^{2} \cdot \mathrm{f}^{2} / 4 \mathrm{~L}
$$

In this example this elongation equals $\Delta \mathrm{l}_{\mathrm{r}}=\pi^{2} \cdot 1^{2} / 4 \cdot 270=0,009 \mathrm{~mm}$.

In relative deformations it equals the following:

$$
\varepsilon=\frac{0,009}{270}=0,00034
$$

In this case, during the heating up to $500{ }^{\circ} \mathrm{C}$ the difference between the temperature elongations of the frame and the workpiece in absolute terms equals $\Delta \mathrm{l}=2,3328 \mathrm{~mm}$, in relative terms for the shaft it equals $\varepsilon=0,00192 \%$. The deformation compliant with the yield limit at this temperature equals

$$
\varepsilon_{T}^{500}=\frac{\sigma_{0,2}^{500}}{E^{500}}=\frac{440}{270}=0,0022>0,00192 \%
$$


The access to the plastic zone is not provided for this ratio of the lengths of the workpiece and the frame. In order to exceed the yield limit, it is necessary to ensure the preliminary heating of the workpiece. The maximum possible difference between the temperature elongations of the workpiece and the shaft is determined, which is possible when the shaft is preliminary heated up to the temperature of $500{ }^{\circ} \mathrm{C}$. Then the difference between the frame and the shaft elongations will be equal to the frame elongation $\Delta \mathrm{L}_{\mathrm{FR}}=4,147 \mathrm{~mm}$, and in the relative deformations it will be $\varepsilon=0,0153 \%$ for the shaft. This difference guarantees the exceedence of the yield limit and, if necessary, provides the correction of the shaft curvature.

\section{Experimental results.Conclusion}

The experimental studies of the thermal power treatment were performed in the following modes: steel $12 \mathrm{X} 18 \mathrm{H} 10 \mathrm{~T}$, air hardening at $1020^{\circ} \mathrm{C}$, tempering at $600{ }^{\circ} \mathrm{C}$ in the frame; steel $30 \mathrm{X} 13$, air hardening at $1020^{\circ} \mathrm{C}$ or higher, tempering at $600^{\circ} \mathrm{C}$ in the frame.

The thermal power treatment of the SW in the frame, combined with the thermal treatment, decreases the initial deformations 6-9 times for steels 12X18H10T and 2.64-3.5 times for steel 30X13; also, it decreases the level of technological residual stresses 1.64-2.3 times. The thermal treatment of the SW in a free state increases the initial deformations 2.4-4.1 times.

\section{References}

1. A.A. Pozdeev, Residual stresses: Theory and applications / A.A.Pozdeev, Y.I. Nyashin, P.V. Trusov (Moscow, Nauka, p. 112 (1982)

2. A.V. Tropotov, Calculation of the residual stresses after the plasto-elastic deformation with the help of the variational method, Pressure Treatment of Metals, issue 8. Sverdlovsk: UPI, pp. 139-143 (1981)

3. A. Gruening, M. Lebsanft, B. Scholtes, Residual Stress State in Tools Used for Thermo-mechanical Metal Forming Processes.Engineering Applications of Residual Stress, Volume 8. Part of the series Conference Proceedings of the Society for Experimental Mechanics Series, pp. 39-45, 25 May 2011.

4. Juan Dong, Jeremy Epp, Alexandre da Silva Rocha, Rafael Menezes Nunes, Hans Werner Zoch, Investigation of the Influence Factors on Distortion in InductionHardened Steel Shafts Manufactured from Gold-Drawn Rod. Metallurgical and Materials Transactions A, pp. 1-12, 25 November 2015

5. Nyashin, V.Y. Kiryukhin, Biological stress in living tissues. The modeling and control problems. Russian Journal of Biomechanics, Vol. 6, No. 3, 2002, pp. 13-31

6. Nyashin, V. Lokhov, F. Ziegler, Stress-free displacement control of structures. “Acta Mechanica”, 175, 2005, pp. 45-56.

7. O.I. Drachev,Manufacturing techniques for low-stiff axisymmetric parts(St. Petersburg, Politekhnika, 2005)

8. Y.D. Vishnyakov, Managing the residual stresses in metals and alloys / Y.D. Vishnyakov, V.D. Piskarev (Moscow, Metallurgia, 1989)

9. Y.I. Nyashin, On managing the process of materials treatment in order to decrease the residual stresses. Applied Mathematics and mechanics, issue 2, 1981. 